\title{
ATELLÂ
}

\section{Bebidas e comidas em celebrações de nascimento e morte: um estudo em comunidades rurais de Sergipe e Bahia}

\author{
Beverages and foods in birth and death celebrations: a study \\ in countryside communities from Sergipe and Bahia
}

\section{Bebidas y comidas en celebraciones de nacimiento y muerte: un estudio en comunidades rurales de Sergipe y Bahia}

\author{
Sônia de Souza Mendonça Menezes \\ Universidade Federal de Sergipe \\ soniamendoncamenezes@gmail.com \\ Luci Mara Bertoni \\ Universidade Estadual do Sudoeste da Bahia \\ profaluci@uesb.edu.br
Rosangela Vasconcelos Raimundo Santos
Universidade Estadual do Sudoeste da Bahia
rosangelavasconcelos@hotmail.com

\begin{abstract}
Resumo
Em algumas comunidades rurais do Brasil, encontramos traços culturais que estão enraizadas no modo de vida de determinadas populações, as quais perpetuam tradições e identificam particularidades vivenciadas em momentos relevantes da sua história. Esses acontecimentos são celebrados e compartilhados entre a família, vizinhos e amigos. Estes sujeitos sociais constroem suas memórias, representações e histórias a partir da relação com as atividades e heranças compartilhadas no encontro entre os tempos curtos e os tempos longos no espaço rural. Ancorado nessa compreensão, o propósito desse estudo consiste em analisar a dimensão simbólica das comidas e bebidas nas celebrações de nascimento e morte em comunidades rurais dos estados de Sergipe e Bahia. Além da revisão teórica, foram realizadas entrevistas em comunidades rurais do estado de Sergipe e Bahia no período de maio de 2016 a janeiro de 2017. Embora não haja relação explícita entre essas comunidades, pudemos perceber muitas semelhanças entre elas na forma de celebrar, no preparo das bebidas e comidas que fazem parte destes rituais que se perpetuam por gerações. Palavras-chave: Comunidades rurais; bebidas e comidas; celebrações nascimento e morte.
\end{abstract}




\begin{abstract}
It is possible to find in some Brazilian countryside communities cultural aspects that are rooted in the way of living of these peoples which perpetuate their traditions and identify specificities that were experienced on important moments of their history. These moments are celebrated and shared among family members, neighbors and friends. These social subjects build their memories, representations and stories from their relations with the activities and inheritances divided in their gatherings for long and short periods of time inside the countryside. Based on the understanding of this topic, this study aims to analyze the symbolic dimension of foods and beverages on birth and death celebrations in countryside communities from the states of Sergipe and Bahia. Besides the theoretical review, interviews were also performed in countryside communities from those states from May 2016 to January 2017. Although there is not any explicit relation among these social groups, we could realize a series of similarities in their way of celebrate, and also the preparing of foods and beverages that are part of these rituals perpetuated throughout generations. Keywords: Countryside communities; Beverages and foods; Birth and death celebrations.
\end{abstract}

\title{
Resumen
}

En algunas comunidades rurales de Brasil encontramos rasgos culturales que están enraizados en el modo de vida de determinadas poblaciones, en las cuales se identifican particularidades vividas en momentos relevantes de su historia. Esos acontecimientos son celebrados y compartidos con la familia, vecinos y amigos. Estos sujetos sociales construyen sus memorias, representaciones e historias desde la relación con las actividades y herencias compartidas en el encuentro en periodos cortos y largos en el espacio rural. Anclado en esta comprensión, el propósito de ese estudio es analizar la dimensión simbólica de las comidas y bebidas en las celebraciones de nacimiento y muerte en comunidades rurales de los estados de Sergipe y Bahia. Además de la revisión teórica, fueron realizadas entrevistas en comunidades rurales de Sergipe e Bahia en el periodo de mayo de 2016 a enero de 2017. Aunque no exista relación explicita entre esas comunidades, fue posible percibir muchas similitudes entre ellas en el modo de celebrar, la preparación de las bebidas y comidas que hacen parte de estos rituales que se perpetuán por generaciones.

Palabras clave: Comunidades rurales; Bebidas y comidas; Celebraciones de nacimiento y muerte.

\section{Introdução}

Como em um tecido, as memórias se entrelaçam à cultura, à oralidade e ao saber fazer de um povo. Muito do que reproduzimos em nosso cotidiano está permeado pelas histórias que (re)criamos ou (re)inventamos a partir de um lugar que nos deu origem e que, muitas vezes, não sabemos, exatamente, qual é. Halbwachs (2004) localiza a família como um dos marcos nos quais aprendemos os diversos aspectos de socialização e nos quais se baseiam nossas memórias individuais que são construídas a partir da memória de um grupo. Assim afirma o autor:

Los recuerdos de familia se desarrollan, a decir verdad, en muchos terrenos diferentes, en las conciencias de los diversos miembros del grupo doméstico: aun cuando están juntos, con mayor razón 
cuando la vida los mantiene alejados, cada cual se acuerda a su manera del pasado familiar común. [...] Si nos quedásemos en la memoria individual, no comprenderíamos sobre todo que los recuerdos de familia reproducen nada más que las circunstancias en las que hemos estado en contacto con tal o cual de nuestros parientes. (HALBWACHS, 2004, p. 175-76).

As memórias são de pessoas e de fatos, de saberes e de fazeres que se perpetuam por gerações. Desta forma, contextualizamos as tradições passadas sobre alguns costumes em momentos de nascimento e morte que são difundidos em comunidades rurais da Bahia e de Sergipe. Não podemos afirmar que há relações estritas entre as tradições dessas duas comunidades, tampouco apontar suas origens, mas é fato que, em diversas localidades do Brasil, há costumes similares. O que destacamos aqui são os diversos usos da comida e da bebida alcoólica difundidos entre a população, a partir de duas pesquisas: uma realizada nas comunidades de Lagoa Nova e Feirinha, nos municípios Nossa Senhora da Glória e Monte Alegre de Sergipe, e Sítio Alto (MENEZES; GOMES, 2016) municípios sertanejos sergipanos, e outra na mesorregião de Vitória da Conquista - BA (BERTONI; SANTOS, 2017; SANTOS, 2017).

Decifrar a geograficidade das comidas e bebidas nas celebrações de nascimento e morte, para além da simples identificação, significa reconhecer a dimensão simbólica e humana das celebrações. Para Claval (1995, p. 255), "alimentar-se, beber e comer: não há terreno de análise mais fascinante para os geógrafos. As relações ecológicas dos seres humanos com seu ambiente exprimem-se diretamente nos consumos alimentares". Alguns alimentos e bebidas estão enraizados na memória de grupos familiares, comunidades rurais, e alguns desses hábitos são transmitidos por diferentes gerações, por vezes ressignificados, alterados mas, a essência continua sendo preservada.

Pesquisar alimentos e bebidas nas celebrações significa descortinar o sentido dos rituais para a vida de homens e mulheres, identificando as relações entre eles, o espaço e os seus desdobramentos, é "interpretar o valor social a elas agregadas" (ALMEIDA, 2005, p. 323). Ao realizarmos uma leitura desses rituais, constatamos que os hábitos alimentares das comunidades e de grupos familiares, "fala da família, de homens e mulheres e da sociedade [...] do conjunto de alimentos disponíveis em cada ecossistema, o que se deve e o que não se deve comer para cada pessoa e estágio de seu ciclo de vida e estágio físico" (WOORTMAM, 2013, p.14). De fato, constatamos nessa pesquisa a relação da comida com a parturiente e as representações construídas em torno desses alimentos. De igual modo, evidenciamos que embora não existam comprovações científicas de sua eficácia, as bebidas eram (e são) popularmente divulgadas e sobre elas circulam também muitas representações. Sua preparação perpassa a sabedoria de homens e mulheres que, também, as consomem e/ou as comercializam. De maneira geral, são feitas por mulheres, visto que a preparação de alimentos e divulgação de receitas perpassam, prioritariamente, o universo feminino ou ao espaço doméstico das mulheres.

Antes de aprofundarmos essas questões, faremos algumas considerações acerca das bebidas alcoólicas que ademais de estarem presentes no nascimento e na morte (e 
milenarmente em outros), seu abuso está relacionado a outros problemas de saúde pública que não serão abordados aqui mas que tem sido sistematicamente estudados em outras pesquisas (BERTONI, 2011; BERTONI, FERNANDES, 2011; BERTONI et al., 2013; SILVA, BERTONI, 2013; BERTONI, 2015).

A bebida alcoólica é bastante difundida no Brasil e está ligada aos mais diversos usos, seja recreativo, religioso ou medicamentoso. Presente na composição dessas bebidas, de acordo com Precioso (2014, p. 7):

[...] o álcool é uma substância que resulta da fermentação de açúcares existentes em diversos produtos de origem vegetal, como frutos e tubérculos, cereais, mel, efetuada por microorganismos, particularmente, as leveduras.

Por ser uma droga ${ }^{1}$ lícita, não é difícil encontrar nas mais diversas regiões brasileiras, costumes arraigados quanto às mais variadas receitas para o uso do álcool para efeitos de cura ou de celebrações. Era comum, por exemplo, encontrar no nordeste do Brasil, as chamadas "garrafadas" que, misturadas a cachaça e ervas, servem para resolver distúrbios sexuais e outros tantos problemas. Em tempos remotos, tão facilmente encontradas nas vendas ou chamadas bodegas, mas quase não vistas, atualmente, com as transformações nesses espaços e a inserção do autosserviço característica das redes de supermercados.

A tradição da garrafada desfaz-se após a década de 1980 com as alterações nos estabelecimentos comerciais nos espaços rural e urbano. Para além do que poderíamos considerar uma "medicina caseira", estão presentes outros costumes como a de velar o corpo de ente querido ou conhecido, tomando cachaça para aquecer o frio e manter-se na roda de conversa.

Partindo dessa perspectiva, este artigo tem como objetivo apresentar uma discussão sobre o uso de comidas e bebidas tradicionais, que estão enraizadas na memória das comunidades rurais e que continuam sendo transmitidas para as gerações. Conforme apontamos, anteriormente, este artigo foi construído a partir de pesquisa de campo em comunidades rurais no estado de Sergipe e na Bahia, além da revisão bibliográfica envolvendo a contribuição de estudos de diferentes áreas do conhecimento. Espera-se aqui contribuir para suscitar novas discussões sobre o lugar das comidas e bebidas tradicionais e o seu uso na contemporaneidade propagando conhecimentos transmitidos por diferentes gerações.

\section{Universo de análise: comunidades rurais sergipanas e baiana}

A configuração do mundo rural desde meados do século XX tem passado por processos de transformação. Os agricultores estão, plena ou parcialmente, integrados aos

\footnotetext{
${ }^{1} \mathrm{O}$ termo droga pode ser definido como "uma designação genérica de toda substância usada, capaz de modificar a função dos organismos vivos, resultando em modificações psicológicas ou de comportamento" (LAPATE, 2001).
} 
mercados. Com os processos de modernização agrícola e difusão técnica prenunciou-se a homogeneização de sistemas produtivos. Contudo, tais mudanças não incidiram em todos os espaços rurais, deste modo, não provocaram o desaparecimento de referenciais específicos, a exemplo das sociabilidades locais ou das horizontalidades e, por conseguinte, da diversidade das práticas e rituais tradicionais.

Pressupõe-se que, nesses territórios tradicionais, o tecido social continua entrelaçado por conexões aglutinadoras como as relações de proximidade, as trocas de saberes entre amigos, vizinhos, parentes e o compadrio que denotam processos de criação de alternativas, com vistas à permanência e à inclusão no meio rural. Alimentadas pelas inter-relações, as atividades realizadas em grupo, entre as famílias, como os antigos "batalhões ${ }^{2}$," são alteradas. Elas atravessaram um momento de (des)uso, (re)formularam-se e, atualmente, são denominadas mutirões. Por sua vez, as festas e celebrações vinculadas ao nascimento e morte continuam como momentos de sociabilidade entre os atores sociais, ressignificadas e alteradas, porém, ainda com a participação popular. Dessa forma, as relações sociais continuam importantes nesse "novo" contexto, (re)configuradas, fruto das mudanças ocorridas no espaço.

Entre as alterações no mundo rural, ocorre a expansão de paradigmas modernos que alteram o uso da terra e, por consequência, geram rupturas e a ressignificação dos rituais, com outros modelos. Entretanto, os homens e mulheres buscam preservar hábitos e costumes, adaptando-os às novidades inclusive aos motes globalizados como o uso dos celulares e das redes sociais. Porém, eles ainda compartilham entre seus pares do acontecer solidário, identificam as forças antagônicas e os interesses comuns, conformam laços identitários e de pertencimentos e recriam "novas práticas”. Em meio à modernização" ou à inserção do uso de técnicas modernas, e embalados por essas mudanças, os camponeses em determinadas comunidades preservam rituais enraizados e os (re)inventam com a inserção das técnicas. A partir da observação e pesquisa nos espaços sertanejos sergipanos e baianos surgiram algumas indagações sobre a relação existente entre a territorialidade dos sertanejos sergipanos e baianos relacionadas às celebrações e rituais festivos no nascimento e rituais na morte, e que traços singularizam a persistência das celebrações do nascimento e da morte e a ruptura da tradição e da identidade dos sertanejos na atualidade.

Buscamos identificar os motes dos homens e mulheres, destacando a maneira como eles concebem e vivenciam as celebrações na contemporaneidade, em um cenário que exprime as ações dos homens e mulheres, "através das suas relações práticas e simbólicas sempre providas de 'teias e tramas' dos significados vividos entre os atores sociais" (BRANDÃO, 1999, p.14). Investigar essas representações torna-se imprescindível para o entendimento do contexto atual desses rituais. Os indivíduos

\footnotetext{
${ }^{2}$ Batalhões-constituíam atividades (no plantio de uma roça, na colheita ou em outras) realizadas por um grupo de formado por amigos, parentes, vizinhos com o objetivo de ajudar o amigo ou um grupo familiar, entretanto, não recebem nenhuma espécie de pagamento. Geralmente, aquele que recebia a ajuda, distribuía aos participantes bebidas(cachaça), comida e iguarias, os batalhões eram regados com música.
} 
buscam resguardar, no território, o seu espaço de luta/de vida, no qual desfrutam juntamente com os seus vizinhos, parentes e amigos das inter-relações, organizam atividades com o seu próximo com o objetivo de preservar símbolos da identidade territorial, traços conferidos na busca de atributos que referenciam especificidades culturais e materiais. Alguns atributos (alimentos, músicas, danças, bebidas...) estão eivados de identificações estereotipadas da identidade. A respeito da construção das identidades, Castells (2000, p.23) esclarece: “[...] vale-se de matéria-prima fornecida pela história, geografia, biologia, instituições produtivas e reprodutivas, pela memória coletiva e por fantasias pessoais". Entretanto, esses elementos são processados pelos sujeitos de forma individual ou grupal sendo paulatinamente reorganizados seus significados de acordo com uma propensão social, cultural enraizada em sua estrutura. Ou seja, buscam preservar suas tradições mas, também, ressignificam atividades com o apoio das redes de sociabilidades ou redes sociais que emergem impulsionadas pela identidade dos participantes (parentesco, vizinhança, amigos) e estruturam o processo.

Ao discutir essa identidade territorial, faz-se necessário adentrar na história da ocupação humana na tentativa de compreender os processos, as razões da preservação, do sentimento de pertencimento enraizados no sertanejo, cristalizado nas celebrações evidenciadas no meio rural, práticas culturais que imprimiram e imprimem marcas eivadas de significados.

O Nordeste semiárido caracteriza-se pelo clima tropical, com duas estações: uma muito seca e outra com chuvas moderadas, pode ocorrer neste período chuvoso a ausência da pluviosidade por um ano ou mais, denotando o fenômeno da seca. A respeito dessa sub-região nordestina Ab’Saber (1985, p. 44) assevera:

O Nordeste seco do Brasil é uma província fitogeográfica das caatingas, onde dominam temperaturas médias anuais muito elevadas e constantes. Os atributos que dão similitude às regiões semi-áridas são sempre de origem climática, hídrica e fitogeográfica, baixos índices de umidade, escassez de chuvas anuais, irregularidade no ritmo das precipitações ao longo dos anos, prolongados por períodos de carência hídrica solos problemáticos tanto do ponto de vista físico quanto geoquímico do solo (solos salinos, solos carbonáticos) e ausência de rios perenes sobretudo no que se refere às drenagens autóctones[...].

A peculiaridade dos signos que expressam o Sertão nordestino está relacionada às questões envolvendo a semiaridez, a vegetação de cactáceas, o movimento migratório e a pobreza da população. A literatura, a música, as artes plásticas registram e ilustram por meio dos seus personagens o fenômeno climático marcante. Mas o Sertão não significa exclusivamente um estereótipo negativo, posiciona-se Rodrigues (2001, p. 28): “o sertão não é sinônimo de miséria, ignorância e isolamento; também é uma realidade a ser vista a partir dos pares riqueza-miséria, secas-chuvas, coronelismo-compadrio, atraso-progresso, embora neles estes conteúdos sociais façam-se presentes”. Para essa autora, existe uma diversidade de personagens, espaços, formas, signos, que aparecem 
de modo contraditório integrados, constituindo o sustentáculo de um sistema de exploração vigente.

Afora os estereótipos negativos, depara-se com representações da cultura sertaneja nas festas, nas celebrações, na alimentação, nas formas de aproveitamento econômico do espaço, persistindo tradições festivas, culturais e econômicas.

A mudança das atividades culturais se processa de forma gradual, cumulativa e histórica. Para desvendá-las, faz-se necessário averiguar os significados para as comunidades atuais bem como as passadas. Nesse processo, implica o acréscimo de novos padrões, não ocorrendo a eliminação de modo totalitário dos padrões então existentes, salvo em casos extremos. Assim, devem ser considerados os atores e suas ações na elaboração das culturas, assim como as "novas" alterações impostas ou construídas por eles. Nessa direção, revelaremos os rituais e celebrações que marcam e fixam importantes momentos vivenciados nas comunidades rurais pesquisadas. Da Matta (1986, p. 112) "nascimentos, batizados, crismas, comunhões, casamentos e funerais todos os momentos que assinalam dramaticamente uma crise de vida e uma passagem na escala da existência social". Tais momentos são marcados pela relação com a religiosidade, na sequência evidenciaremos os rituais das celebrações do nascimento e àquelas relativas à morte.

\section{Comida e bebida no nascimento: cultura transmitida por gerações}

O alimento é muito mais que um veículo de nutrição orgânica, é um resultado de fatores "socioculturais" que influenciam os hábitos alimentares (CASTRO, 1965). Logo, a escolha de alimentos ou gêneros alimentícios não se apresenta isenta dos aspectos culturais. Para Da Matta (1986), esses aspectos expressam uma identidade.

A alimentação sertaneja consiste em uma das representações simbólicas mais autênticas da sua cultura. Os delineamentos dessa culinária, as suas peculiaridades estão espelhadas no cotidiano dos sertanejos mesmo em áreas distantes do seu habitat. A observação dos traços culturais da alimentação sertaneja, tal como se apresentava no passado e na atualidade, proporciona uma compreensão mais ampla dos sertanejos. Esta pesquisa faz uma incursão na história de duas celebrações vivenciadas por esses homens e mulheres, o que contribuirá para entender a bebida e a comida como uma marca identitária.

Algumas comidas destacadas pelos(as) entrevistados(as), são recomendadas pelos membros da família como "prescrições alimentares, isto é, o que se deve comer" ressaltou em suas pesquisas Woortmann (2013, p.14). Embora a autora não tenha estudado essas comunidades observamos que, sobretudo no caso das parturientes, essas crenças a respeito do seu valor nutricional foram transmitidas por diferentes gerações outrora. Percebe-se que, ao estudar determinados tipos de alimentos, não se deve buscar somente o aspecto orgânico, mas também as formas de produção, os valores culturais, os significados e as crenças existentes em torno da alimentação.

Claval (1999) reafirma a sua posição ao destacar essa função geográfica da alimentação "nos introduz a uma das formas mais ricas de interações humanas". Os 
homens não devem ser compreendidos como meros consumidores, pois estão inseridos dentro de grupos sociais. Esse, pelo ato alimentar, perpetua sua história, reforçam seus laços sociais, conduzem e impulsionam a configuração de atividades que se apresentam inter-relacionadas com o meio geográfico e traduz em estratégia de permanência no meio rural. Os alimentos representam a ligação mais primitiva entre natureza e outrora, fazendo parte da raiz que liga a um povo, uma comunidade ou um grupo à sua terra e à alma de sua história (FISCHLER, 1995).

Constituía uma tradição sertaneja a alimentação diferenciada das parturientes. As mulheres alimentavam-se de comidas não carregadas baseadas na carne de galinha acompanhada de pirão e arroz, restringindo outras aves como os perus e uma diversidade de alimentos. Tradicionalmente, serviam uma sobremesa, a denominada espécie ${ }^{3}$, preparada por algum membro da família ou presenteada pelas comadres e vizinhas.

O consumo desse doce tinha como finalidade aumentar a produção de leite ou facilitar o aleitamento materno. Porém, seu consumo não se restringia exclusivamente às parturientes, compartilhava-se com toda a família. Segundo a memória dos(as) sertanejos(as) idosos(as), comumente fazia parte da tradição o agricultor plantar o gergelim anualmente tendo em vista que as mulheres tinham um filho a cada ano, portanto, deveria o sertanejo precavido guardar esse alimento para o preparo do referido doce. Cabia às mulheres fazer a criação de aves (galinhas), escolher algumas para a engorda e, posteriormente, alimentar-se no pós-parto. As famílias geravam anualmente um filho, o que resultava em uma grande prole, explicada como força de trabalho essencial para a reprodução (MENEZES, 2015). Como parte da tradição no ritual do pós-parto, era oferecida aos visitantes antes de servir, durante e pós o almoço a meladinha ${ }^{4}$. A tradição da meladinha foi retratada por Luiz Gonzaga (1973) na música Samarica Parteira que conta a história da realização dos partos no sertão nordestino e o ritual desde a busca da parteira até o momento do nascimento do filho...

[...]Capitão Barbino foi lá detrás da porta, pegou o bacamarte ...que tava guardado há mais de oito dia, chegou no terreiro, distambocou no ôco do mundo ... deu um tiro tão danado que lascou o cano. Samarica dixe : Lascou, Capitão? Lascou Samarica, Ha! Mas em redor de 7 légua, num tem fi d'uma égua que num tenha escutado. Prepare aí a meladinha, prepare a meladinha Ha...!

\footnotetext{
${ }^{3}$ Espécie: doce produzido a base de gergelim, ou amendoim, utiliza-se ainda como ingredientes a farinha de mandioca e, na calda, açúcar ou rapadura, a pimenta do reino, o cravo e a canela. Esta mistura resultará em um sabor adocicado e quente da pimenta.

${ }^{4}$ Meladinha- uma infusão de mel de abelha com cachaça maturada durante vários meses. Em algumas áreas, adotavam a prática do uso de folhas dentro da infusão como a erva-cidreira, o capim-santo, juntamente com cravo, canela e pimenta-do-reino. Ainda outros sertanejos utilizavam as folhas da arruda no preparo que, segundo as suas crenças, tinha a finalidade de retirar os "olhos ruins" da casa e da criança recém-nascida.
} 
As entrevistadas residentes no sertão sergipano destacaram que após dez ou quinze dias do parto eram feitas e ainda continua sendo realizado os denominados banquetes nos quais reuniam familiares, amigos, para comemorar o nascimento. Nessa celebração eram oferecidos o pirão de capão, a farofa, arroz, entre outros ingredientes e a meladinha. $\mathrm{Na}$ atualidade ainda continuam a realizar os banquetes, porém, nessas comunidades sertanejas já não se fazem a meladinha, são oferecidas outras bebidas alcóolicas como a cerveja e o whisky. Tal mudança denota o avanço das empresas de cerveja e a força do marketing da propaganda atingindo comunidades rurais de igual modo, foi identificado por Menezes (2013) com as transformações nas comidas, motivadas pela inserção do meio técnico-científico, pelo poder da propaganda utilizada pelos grandes conglomerados nacionais e transnacionais.

Entretanto, na comunidade quilombola Sítio Alto (2015) em Simão Dias verificamos o uso acentuado da meladinha como um ritual pós-parto utilizado pela parturiente assim como, pelos visitantes.

Diferentemente do ritual que ocorria no Sertão sergipano com os denominados banquetes, em Sítio Alto a comida da parturiente era constituída de pirão de capão, não usava condimentos e nem temperos, como coentro, cebola vermelha, pimentão, nem corante. A comida era branca. E, as mulheres costumavam tomar meladinha após o parto, uma dose pequena para limpar o resto do parto. Dentre os diversos usos do álcool, ainda é comum o costume de "curtir" a cachaça com ervas quando se anuncia que a mulher está grávida, e essa mistura é oferecida à parturiente e aos convidados quando do nascimento da criança. Prepara-se a bebida, após submetida a processo de infusão, espera-se três dias, até a mistura adquirir uma coloração esverdeada.

Antes do bebê nascer, elas [as mulheres da comunidade] preparavam a bebida, som os seguintes ingredientes: cachaça, cebola branca (Allium cepa), hortelã (Mentha spicata), alecrim (Rosmarinus officianalis), "amisterado" (mistura de condimentos diversos), alfazema (Lavandula officinalis), barreira branca (pista taxonômica não localizada) e uma folha pequena de arruda (Ruta graveolens) e mel.

Na mesorregião de Vitória da Conquista (BA), os costumes são muito similares em relação a comidas e bebidas oferecidas quando nasce uma criança no sertão sergipano. A temperada, assim denominada nesta localidade, pode ser preparada à base de aguardente com raízes e folhas. Junto com a temperada, serve-se, também, o pirão de parida. O nascimento de uma criança é motivo de muita alegria nas comunidades rurais, as famílias criam frangos durante toda a gestação para quando a criança nascer possa se reunir e fazer o tradicional pirão de parida. Costume antigo que se perpetua há muitos anos, passado de mãe para filha, o pirão normalmente é servido aos domingos acompanhado da temperada, como forma de confraternização. O preparo do pirão de parida e da temperada é um costume que já está sedimentado na memória da comunidade rural sendo compartilhado coletivamente. De acordo com Santos (2017), este costume ainda é reproduzido pela população local que assim afirma: 
[...] Tem de oferecer um golim oferece a quem quiser de 4 a 5 dias quando a mulher pári, coloca hortelã, losna, açafrão, pimenta do reino só um pouquinho na cachaça (E 1).

[...] a mulher pári antes faz a cachaça temperada com hortelã, fredegoso, cebola e oferece aos convidados (E 2).

[...] faz a temperada com losna, cebola e alho. O marido oferece para quem chega. Bebe só um pouquinho. Só pra comemorar o nascimento da criança. Por alegria (E 5).

[...] agradar os amigos que chega. Com losna, arruda, cebola branca e alho e pinga. O marido oferece as pessoas, algumas paridas também bebe. É difícil ter uma que não bebe (E 6).

[...] quando eu ganhei meus fí tudo, eu dei. Bota losna na cachaça pra ficar gostosa e dá pra que visita a parida dá junto com o pirão de galinha, fica é gostosa a temperada da parida (E 10).

[...] cachaça com remédio: losna, hortelã. Toda casa tem quando a mulher ganha neném. A mulher que pariu tem que tomar pra ter forças (E 14).

As celebrações festivas relacionadas ao nascimento são vivenciados como rituais e em algumas comunidades, como vimos até aqui, constituem ocasiões especiais nas quais os esses momentos relevantes são culturalmente transmitidos por diferentes gerações.

\section{Comida e bebida na morte: ritual que definha-se na atualidade}

Os rituais marcam a vida das sociedades, assinalam atos rotineiros vivenciados no cotidiano, mas, sobretudo, eventos significativos na vida das pessoas como o nascimento, a formatura, o casamento e o falecimento. Após abordar as celebrações realizadas no nascimento retratando a comida das parturientes e a bebida (consumida por elas e oferecidas aos visitantes), faremos considerações dos rituais relacionados à morte.

Reis (1991), ao abordar em seus estudos a morte no século XIX ressalta que tal fato deveria ser divulgado para que um número elevado de pessoas participassem do funeral e, desse jeito, evitasse que os maus espíritos se aproximassem do defunto. Para atrair os participantes, os familiares distribuíam comidas e bebidas, sobretudo as cachaças. Desse modo, as pessoas continuariam no velório até o momento do funeral. A cerimônia de velar o defunto, constituía na encomendação da alma por meio das orações cantadas, recitadas como as "incelências" - tipo de canto fúnebre, de matriz popular, vastamente difundido no interior do Brasil nas denominadas sentinelas.

As sentinelas constituem, no passado e no presente, como um momento de sociabilidade no qual as lamúrias e os choros ocorrem, geralmente no espaço de dentro da casa. Porém, o uso de bebidas (cachaça) juntamente com a prática de contar piadas e de rememorar os feitos do morto são evidenciados no espaço de fora da casa. 
Oliveira (2013), em suas pesquisas a respeito da alimentação dos migrantes de Cabo Verde residentes em Lisboa, ressalta a importância da alimentação e da bebida nos rituais fúnebres como uma tradição mantida pelos cabo-verdianos. $\mathrm{O}$ autor assevera que no bairro de Alto da Cova da Moura, situado na área metropolitana de Lisboa, os migrantes procuram manter suas tradições, e as práticas gastronômicas estão associadas à alegria e à tristeza. Diferentemente da cozinha de festa onde reina a alegria e a comida é elaborada em várias panelas com tipos diferenciados. No entanto, nos funerais é oferecido geralmente um só tipo de comida. $\mathrm{O}$ autor apresenta a fala de um entrevistado que afirma "quando há um funeral depois na volta há sempre aquela panela de canja de galinha, 'canja do finado' [...]tem que haver sempre comida e bebida" (OLIVEIRA, 2013, p.54-55).

Em Sergipe, constatamos em várias comunidades rurais sertanejas que a prática de "beber o morto" é considerada por alguns como um sacrilégio, algo que destoa o ritual fúnebre. Entretanto, foi evidenciado por outros entrevistados que para suportar a noite acordado os homens ficam no lado de fora das casas conversando e bebendo cachaça. De acordo com os entrevistados, quando o morto bebia rotineiramente, os seus amigos e companheiros passam a noite velando no espaço de fora regado com a bebida, alguns ainda alegam que é para passar o sono, outros para reduzir o frio sobretudo, nos meses de inverno. Na pesquisa nos municípios de Nossa Senhora da Glória, Monte Alegre de Sergipe e a comunidade Sítio Alto em Simão Dias foi evidenciada ainda pelos entrevistados que o avanço das empresas que organizam o funeral, essa prática tem sido reduzida, além disso, com a expansão dos grupos evangélicos esse ritual também diminuiu. Entretanto, perduram as características semelhantes àquelas evidenciadas por Reis (1991) e Oliveira (2013).

No caso das celebrações fúnebres embora estejam marcadas pela tristeza, têm as suas características específicas, mas, envolvem comida e bebida.

Na comunidade Sitio Alto em Simão Dias quando ocorria o falecimento de um morador, a comunidade reunia para rezar e eram oferecidas comidas para aqueles que ficavam nas denominadas sentinelas, conforme dissemos anteriormente. Em algumas casas, as pessoas ofereciam cachaça, mas quando não bebiam, também respeitavam. Durante a noite toda, cantavam e bebiam cachaça e acendiam o fogo no meio do terreno, um costume que, de acordo com as entrevistadas, inclusive, o padre ressaltava para a comunidade que eles deveriam manter as tradições.

$\mathrm{Na}$ comunidade baiana pesquisada, podemos constatar que, apesar de ser um evento doloroso para a família, a morte exige o compromisso de realizar uma celebração com muita comida e bebida (cachaça). Tal tradição é comumente conhecida como "beber o morto". A tradição de beber o morto é muito antiga, ocorre no momento do velório, no qual os conhecidos do falecido se reúnem para honrar o morto e executar os preparativos do sepultamento. No espaço rural são comuns sepultamentos longos sendo, portanto, oferecidos café, comida e bebidas alcoólicas. Muitas vezes, sob o efeito do álcool e das lembranças dos vivos, os velórios acabam se tornando festivos. Quando alguém morre, se for alguém que tem um poder aquisitivo maior, é feito um verdadeiro 
banquete com carne, frango e muita bebida alcoólica, caso contrário é servida somente a cachaça. $\mathrm{O}$ consumo de bebidas alcoólicas nas celebrações é uma constante e faz parte da história dessa comunidade. Conforme relatos de um dos agentes de saúde local, algumas pessoas deixam de visitar as famílias se não tiver bebida alcoólica para oferecer. A falta da bebida alcoólica pode ser caracterizada como ato desrespeitoso à figura do morto. Conforme os relatos de pessoas da comunidade:

[...] o povo vai embora se não oferecer, pinga pura (E 2).

[...] bebe o morto. Pinga pra quem quer beber. É costume (E 3).

[...] mais que eles bota é muita cachaça pro povo beber. Quando meu pai morreu a cachaça lá em casa foi até umas hora (E 4).

[...] bebe e muito o morto. A noite toda. Quando morre alguém da casa o dono da casa compra cachaça e da pro povo (E 9).

[...] quando a pessoa tá morta bebe pra rezar. Quando não tem a bebida sai com raiva falando. Oferece café e cachaça. Os que vai abrir a cova no cemitério leva o litro de cachaça para abrir a cova. Se não levar não abre a cova (E 16).

[...] quando morre alguém aqui eles dão cachaça a noite toda ao povo. Dão para passar a noite. Se não der o povo vai embora e o corpo fica sozinho (E19). (SANTOS, 2017).

A prática de beber o morto retrata o valor simbólico que tal evento representa na vida dessa comunidade. Segundo Silva e Negreiros (2012, p.01), "as ações humanas comportam um significado histórico que traduzem realidades e códigos culturais, as quais comportam valores sociais e culturais constituídos por determinado grupamento social". Desse modo, então, os hábitos e costumes de consumir comidas típicas da região e de consumir bebidas alcoólicas nos eventos fúnebres podem ser representações culturais dessa população, as quais constituem símbolos e valores sociais que traduzem seu modo de vida.

\section{Considerações finais}

O estudo realizado nas comunidades rurais aqui apresentadas buscou mostrar como as tradições culturais de determinadas localidades, embora não tragam relações explícitas entre si, são similares em lugares distintos. Atualmente, embora essas práticas e rituais relacionados ao nascimento e à morte tenham passado por ressignificações, entendemos que essas manifestações culturais constituem representações nutridas por sentimentos de reciprocidade e pertencimento nas comunidades rurais pesquisadas. As lembranças e memórias relativas às celebrações ou rituais no nascimento e na morte indicam a permanência de costumes, que persistem no espaço vivido dessas comunidades.

Os saberes, fazeres e rituais são passados por gerações e esperamos que se perpetuem apesar das grandes pressões mercadológicas que vêm se constituindo na perda de identidade das pessoas e das comunidades. Por isso, a importância de se aprender e divulgar tais práticas para que não se dissolvam diante da difusão de se consumir apenas aquilo que é moda e que não tem história, tampouco tradição. 


\section{Referências}

AB’SABER, A. Os Sertões: a originalidade da terra. Ciência Hoje, Sociedade Brasileira para o Progresso da Ciência, vol 03, n¹8, maio/junho 1985.

ALMEIDA. M. G de. Tantos cerrados: múltiplas abordagens sobre a biogeodiversidade e singularidade cultural. Goiânia: Vieira, 2005.

BERTONI, L. M.; SANTOS, R. V. R. Alcoolismo e meio rural. Revista Geonordeste, n. 1, 2017. p. 98-113.

BERTONI, L. M. Educação, juventude e alcoolismo. In: MAGALHÃES, L. D. R.; CASIMIRO, A. P. B. S.; ALVES, A. E. S. (Org.). Ensaios sobre história, ciência e educação. Campinas - SP: Alínea, 2011.

BERTONI, L. M. M. Se beber não dirija: representações, juventude e publicidade de bebidas alcoólicas. Campinas: Librum, 2015.

BERTONI, L. M. et al. Prevenção às drogas e ao bullying nas escolas:uma questão de direitos humanos e educação. In: BERTONI, L. M.; MORORÓ, L. P.; SANT'ANA, C. C. (Org.). Desafios epistemológicos das ciências na atualidade. Bauru - SP: Canal 6, 2013.

BERTONI, L. M.; FERNANDES, A. V. M. Tolerância zero: reflexões sobre a história do alcoolismo e as prevenções ao uso abusivo de álcool e drogas. In: ALMEIDA, J. R. M. de; MAGALHÃES, L. D. R.; BERTONI, L. M. (Org.). As redes científicas e o desenvolvimento da pesquisa e da extensão: perspectivas multidisciplinares. São Carlos -SP: Pedro \& João, 2011.

BRANDÃO, C. $O$ afeto da terra. Campinas, SP: EdUNICAMP. 1999.

CASTELLS, M. O poder da identidade. Trad. Klauss Brandini Gerhardt.Vol.II. 2. ed. São Paulo: Paz e Terra, 2000.

CASTRO, J. de. Geografia da fome: o dilema brasileiro: pão ou aço. 9. ed. São Paulo: Brasiliense. 1965.

CLAVAL, P. A Geografia cultural: o estado da arte. In: ROSENDAHL. Z., CORREA R. L. (Org.). Manifestações da cultura no espaço. Rio de Janeiro: EdUERJ,1999.

CLAVAL, P. A geografia cultural. Trad. Luiz Fugazzola Pimenta e Margareth Pimenta. Forianopólis: EdUFSC, 1995.

DA MATTA, R. O que faz o brasil, Brasil? 5. ed. Rio de Janeiro: Rocco, 1986.

FISCHLER, C. El (h)omnivoro: el gusto, la cocina y el cuerpo. Barcelona: Amagrama,1995.

HALBWACHS, M. Los marcos sociales de la memoria. Barcelona: Antropos, 2004.

LAPATE, V. Hora Zero: a independência das drogas - antes que os problemas cheguem. São Paulo: Scortecci, 2001. 
GONZAGA, L. Samarica Parteira. 1973. Disponível em: <www.luizluagonzaga.com.br/menu_letras.html> Acesso em: 17 maio. 2017.

MENEZES, S. de S. M.; GOMES, R. de J. Tradições, saberes e fazeres do coração-de-negro Sítio Alto - Simão Dias Sergipe. In: FAGUNDES, A.; FAGUNDES, R.; MENEZES, S. de S. M. Cultura, tradições e segurança alimentar da comunidade de Sítio Alto, Simão Dias, Sergipe. Aracaju: J. Andrade, 2016.

MENEZES, S. de S. M. Comida de ontem, comida de hoje. o que mudou na alimentação das comunidades tradicionais sertanejas? OLAM: Sociedade e Teconologia. Ano XIII, v. 1, n. 2, julho/dezembro p.32-58.2013.

MENEZES, S. de S. M. MENEZES. Sônia de Souza Mendonça. Queijo artesanal Configurações territoriais- Experiências Escalares do Global ao Local( O caso de Sergipe). 1. ed. São Cristóvão: Editora da UFS, 2015.

OLIVEIRA, T. S. de. Identidade e Memória práticas alimentares cabo-verdianas num contexto migratório. Revista Habitus: Vol11, n.1 Goiânia, 2013. p.35-62.

REIS, J. J. A morte é uma festa: ritos fúnebres e revolta popular no Brasil do século XIX. São Paulo: Companhia das Letras, 1991.

RODRIGUES, M. de F. F. Sertão no Plural: da linguagem geográfica ao território da diferença. 2001. 253f. Tese (Doutorado em Geografia Humana) Universidade de São Paulo, São Paulo, 2001.

SANTOS, R. V. R. Representações sociais de homens e mulheres do interior baiano sobre os usos do álcool. Dissertação (Mestrado em Memória: Linguagem e Sociedade). Universidade Estadual do Sudoeste da Bahia, 2017.

SILVA, A. X. da; BERTONI, L. M. Uso de drogas entre discentes do curso de pedagogia. Revista Perspectivas em Diálogo: revista de educação e sociedade, v. 1, p. 14-19, 2014.

WOORTMANN, E. F. A comida como linguagem. Habitus.v.11, n.1. 2013, p.13-34.

Sônia Mendonça de Souza Menezes

Doutora em Geografia pela Universidade Federal de Sergipe (UFS). Atualmente é Professora Adjunto da Universidade Federal de Sergipe (UFS), onde também atua como Coordenadora e docente do Programa de Pós-Graduação em Geografia (PPGEO/UFS). É líder do grupo de estudos e pesquisas sobre Alimentos e Manifestações Tradicionais - GRUPAM/UFS.

Rua: Lourival Chagas, 143, CEP 49025-390, Aracaju - SE

Email: soniamendoncamenezes@gmail.com 


\section{Luci Mara Bertoni}

Doutora em Educação Escolar pela Universidade Estadual Paulista com Pós-doutorado pela Universidade de Brasília (UnB) e pela Universidade de Santiago de Compostela (USC/Espanha). Atualmente é Professora Plena da Universidade Estadual do Sudoeste da Bahia (UESB), onde também atua como docente do Programa de Pós-Graduação em Memória: Linguagem e Sociedade (PPGMLS/UESB). É líder do grupo de estudos e pesquisas em Gênero, Políticas, Álcool e Drogas (GePAD/Museu Pedagógico).

Rua D, 206, CEP 45026-110, Vitória da Conquista - BA

Email: profaluci@uesb.edu.br

Rosangela Vasconcelos Raimundo Santos

Mestre pelo Programa de Pós-Graduação em Memória: Linguagem e Sociedade (PPGMLS/UESB). Enfermeira na prefeitura municipal de Vitória da Conquista - BA.

Av. Franklin Ferraz, 1251, CEP 45055-075, Vitória da Conquista - BA

Email: rosangelavasconcelos@hotmail.com 